\title{
Tectónica de una parte de la Zona de Poza Rica entre el antiguo Continente de Oaxaca y la Plataforma Tecolutla-Tuxpan
}

Eliseo Reyes Domínguez

Superintendencia de Exploración-Pemex

Poza Rica, Ver.

\section{RESUMEN}

Se presenta un análisis regional de las características tectónicas y paleogeográficas de una parte de la Zona de Poza Rica. Se sugiere que deben analizarse los procesos geológicos, principalmente tectónicos, con más detenimiento y se postula que de esos estudios depende la correcta interpretación en la búsqueda de los hidrocarburos.

\section{ABSTRACT}

A regional analysis on the tectonic and paleogeographic characteristics of a portion of the Poza Rica District is given. It is suggested that the geological processes, chiefly tectonics, should be analyzed in detail at the same time, it is postulated that the correct interpretation in the oil exploration depends on these tectonic and paleogeographic studies.

\section{INTRODUCCION}

Para entender la evolución tectónica y paleogeográfica de una parte de la zona de Poza Rica, es necesario analizar regionalmente estas características como un todo, desde los antiguos continentes prepaleozoicos a las formaciones modernas depositadas; de esta manera podrán determinarse ciclos y etapas tectónicas que pueden diferenciarse de poniente a oriente de la manera siguiente:

1.-Ciclo Mazitzi

2.-Cic1o Huayacocotla

\section{3.-Ciclo Sierra Madre}

El primero, comprende del Paleozóico medio al Triásico; el segundo del Jurásico Inferior al Medio y el tercero, del Jurásico Superior al Eoceno Medio. De esta manera quedan comprendidas franjas o zonas bien delimitadas cuya estratigrafía se establece con características específicas que se pueden diferenciar una de otra.

\section{ZONA DE TEHUACAN}

Comprende lo que se ha denominado Antiguo Continente Oaxaqueño, Paleopenínsula de Oaxaca y Plataforma de Oaxaca.

En esta zona se tiene la siguiente estratigrafía. (Figura 1):

\section{COLUMNAS ESTRATIGRAFICAS}

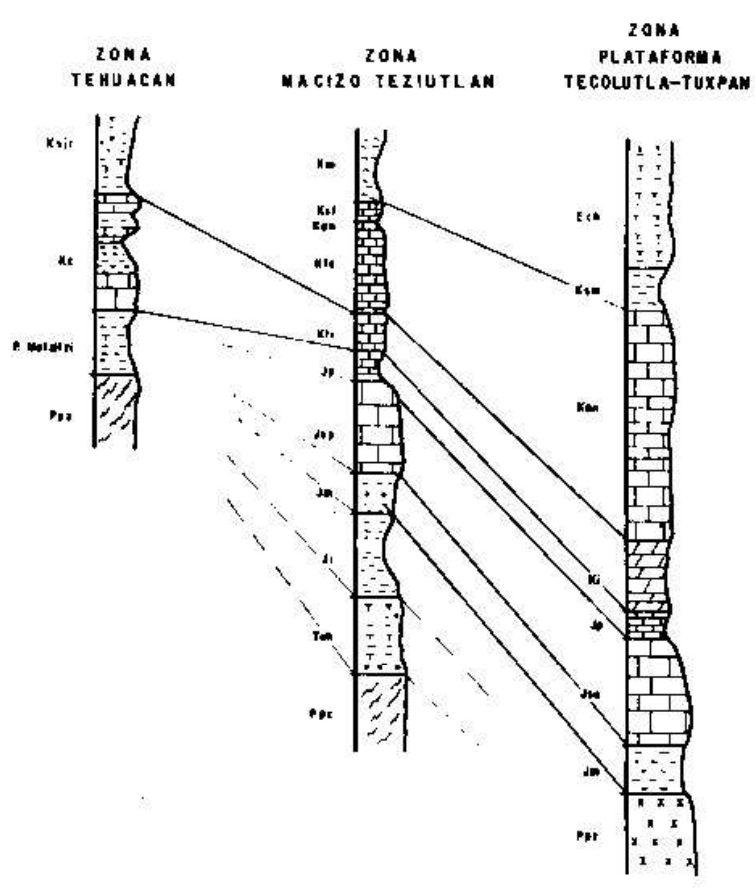


El zócalo de Tehuacán, está constituido por rocas metamórficas de edad Pre-pensilvánicas (Denominadas tentativamente Esquistos Acatlán).

\section{Paleozoico:}

Está constituido por lutitas de color obscuro que alternan con areniscas. de grano fino de espesor delgado, con algunos horizontes de conglomerado de fragmentos de cuarzo, estas rocas tienen un espesor de más de $500 \mathrm{~m}$. y descansan en discordancia sobre los esquistos Acatlán; se les asigna una edad Pensilvánico-Pérmico,

Sobre las rocas antes citadas, sobreyacen en discordancia las formaciones del Cretácico Inferior y Medio, constituidas por rocas de ambiente somero y Plataforma, representadas por la Formación Zapotitlán y San Juan Raya.

\section{ZONA ALTO TEZIUTLAN}

La estratigrafía del Alto de Teziutlán, se construye sobre un zócalo de rocas metamórficas que en principio son equivalentes en edad a los esquistos Acatlán, pero que, para fines de nomendatura lo denominaremos "Esquistos Teziutecos", sobre los que descansa la columna sedimentaria de la Sierra Madre Oriental.

\section{Triásico}

Está constituido por rocas continentales con un espesor de más de $200 \mathrm{~m}$. formado por conglomerados que alternan con limolitas rojas y areniscas de grano grueso, de estratificación cruzada, que descansan en discordancia sobre rocas Prepaleozóicas.

Al igual que en el área de Tehuacán, se tiene una gruesa sección de más de $500 \mathrm{~m}$ de sedimentos continentales formados por limolitas rojizas y conglomerados que descansan en discordancia sobre los esquistos Teziutecos.

\section{Jurásico Inferior:}

El Jurásico Inferior, está constituído en la base por una serie de sedimentos flysch formados por lutitas laminares marinas y areniscas cuarcíferas de grano fino; hacia su cima alternan con capas de conglomerado, alcanzando un espesor de más de $500 \mathrm{~m}$.

\section{Jurásico Medio.'}

El Jurásico Medio cierra el ciclo orogénico Con una facies estructural, rica en depósitos volcánicos y ro- cas efusivas, como se observan en el área de Mazatepec, y que tentativamente se le ha denominado como formación Tenexcate, de espesor variable, de unos cuantos metros a más de 300 , descansa en discordancia angular sobre los sedimentos del Jurásico Inferior.

\section{Jurásico Superior:}

El Jurásico Superior, se caracteriza por sedimentos marinos de plataforma y cuenca, de poco espesor; representados por las Fomaciones San Pedro, Tamán y Pimienta, con un espesor de $70 \mathrm{~m}$. aproximadamente,

\section{Cretácico:}

El cretácico, lo constituyen formacioues de cuenca representados por la Formación Tamaulipas Inferior, Tamaulipas Superior, Agua Nueva y San Felipe, constituidas principalmente por calizas de estratificación mediana a delgada, que alternan con delgadas capas de lutitas calcáreas, Estas formaciones, alcanzan un espesor no mayor de $100 \mathrm{~m}$.

\section{ZONA DE TECOLUTLA Y TUXPAN}

Esta zona queda incluida dentro del Sistema Huayacotla constituida principalmente por un zócalo granítico de edad Permnica?, sobre el que descansa una columna de rocas de plataforma, principalmente del Jurásico Superior y del Cretácico Medio; es una de las zonas más productoras de hidrocarburos conocidas en México.

\section{Paleoceono-Eoceno Medio:}

El Terciario, está formado principalmente por sedimentos terrígenos f1ysch que vienen a rellenar y constituir la Cuenca Cenozoica Tampico Misantla.

\section{PALEOGEOGRAFIA}

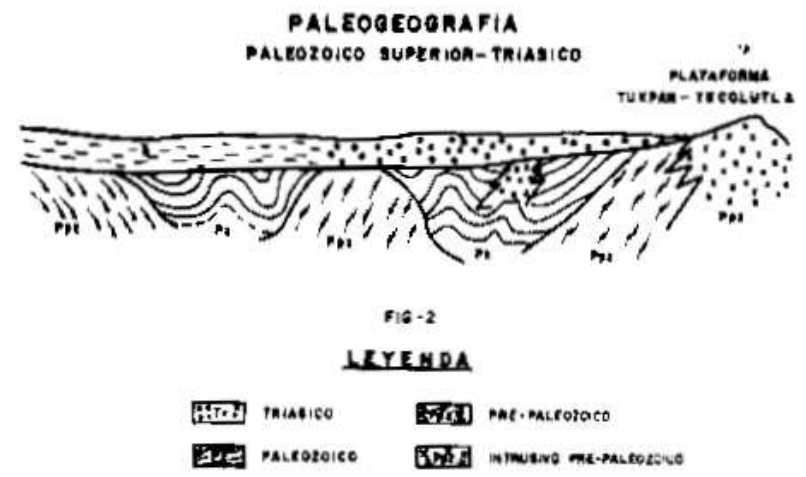


En la Fig. No. 2, se muestra que los sedimentos paleozoicos, descansan en discordancia sobre los esquistos Acatlán, los que al cierre del Paleozoico Superior son fuertemente plegados como consecuencia de un orógeno, que provoca esfuerzos de compresión y que da por resultado la formación de grandes masas graníticas, con mayor desarrollo en el área de Tuxpan y Tecolutla. El Triásico, culmina esta etapa orogénica a través de una intensa erosión, para dar lugar a depósitos sedimentarios continentales de la Formación Huizachal.

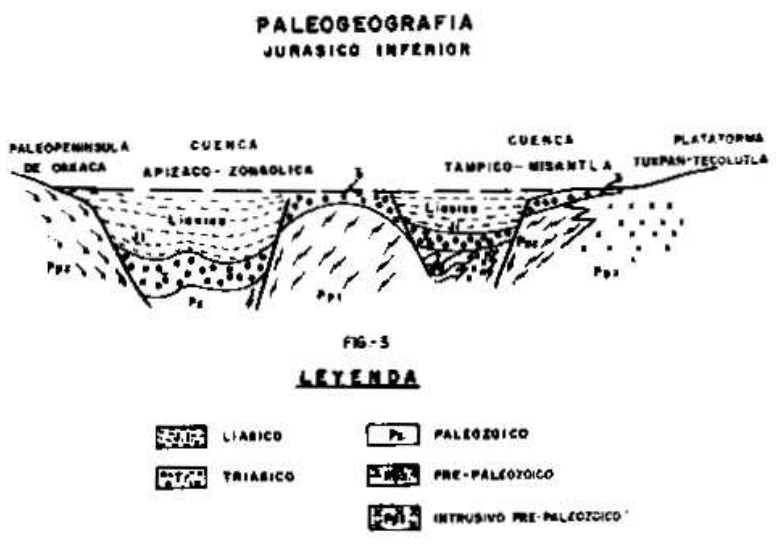

Al finalizar el Triásico en estas áreas, se generan esfuerzos tensionales que provocan afallamientos en grandes bloques, para formar una serie de profundas fosas y altos sobresalientes; lo que ocasiona que en el Liásico se acumulen grandes espesores de sedimentos marinos y continentales del Jurásico Inferior (Fig. No. 3). Estos volúmenes de sedimentos fueron deformados fuertemente a semejanza de lo ocurrido en el Paleozoico Superior, con formación de masas intrusivas que afectan a los propios sedimentos y que se canalizan a través de los planos de falla. Los bloques resultantes de la Tafrogenia Triá-
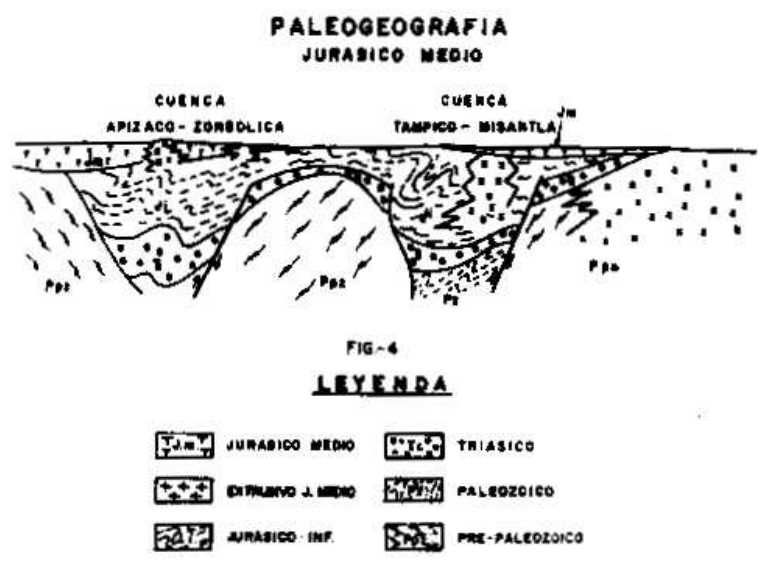

sica, (Palizada) fueron rellenados por sedimentos Liásicos, los cuales también sufren esfuerzos compresionales de cuyos resultados orogénicos, con posterior erosión, se originan depósitos de sedimentos continentales del Jurásico Medio; sin embargo, en esta época, ocurren reacciones contrarias para provocar dislocamiento por esfuerzos tensionales, los que originan la expulsión de rocas básicas dentro de la misma formación, y que caracterizan a la Formación Tenexcate. Figura No. 4. Durante el Jurásico Superior y Cretácico, (Figura No. 5) las fallas principales que dieron origen a los pilares del Triásico, continúan actuando, de tal manera que grandes elevaciones quedan alineadas y separadas por depresiones, como son las Cuencas Mesozoicas de ApizacoZongolica y Tampico-Misantla. Estas grandes unidades son las causantes de las diversas facies sedimentarias que se observan en las rocas de esta época las cuales son afectadas posterionnente por la gran Revolución Laramide que finalmente da lugar al orógeno principal, del gran Geosinclinal Mexicano denominado Sierra Madre Oriental.

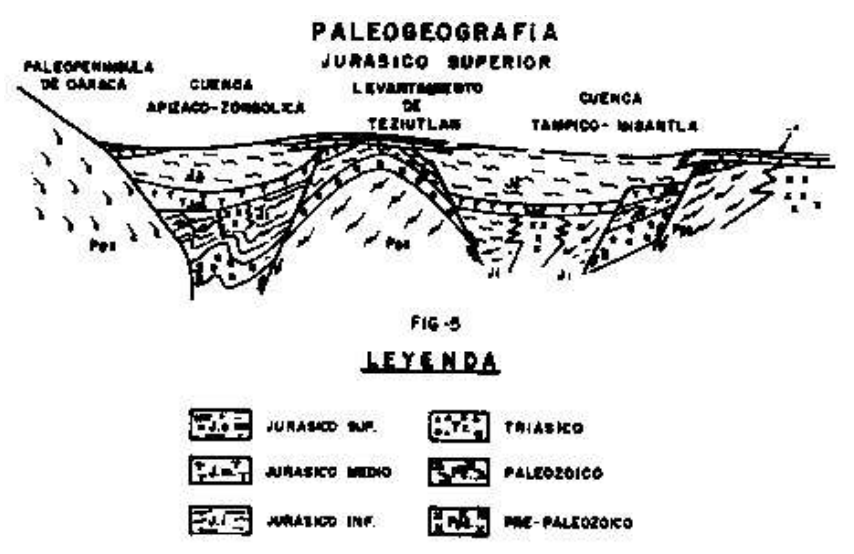

Dentro de la evaluación económica de las unidades tectónicas a que se hace alusión en párrafos anteriores, es necesario entender la influencia que tuvieron sobre el depósito de los sedimentos marinos y continentales en las diferentes épocas, así como la influencia que han tenido en las estructuras principales y a los alineamientos estructurales Predominantes, tanto como de su transfonnación a través de dichas épocas. De acuerdo con esto, es necesario definir:

\section{1.-Que es un basamento.}

Muchos autores denominan basamento, al zócalo marino sobre el que descansa la columna sedimentaria a partir del paleozoico, otros lo consideran 
como el complejo metamórfico, forImado por rocas metamórficas de edad Paleozoicas o prePaleozoicas principalmente.

Algunos autores le llaman basamento económico, refiriéndose a que en la base de una columna geológica no existen mas rocas sedimentarias, sin embargo, es común manejar el término basamento indistintamente en cualquiera de las acepciones antes mencionadas. Frecuentemente al hablar de las provincias petroleras del Este de México, se dice que el basamento ha tenido influencia en el depósito de rocas de plataforma del Jurásico Superior o del Cretácico. Sin embargo al analizar estos conceptos a la luz de la información de los pozos perforados, se tiene que, en muy escasos pozos los sedimentos de plataforma del Jurásico, descansan sobre rocas intrusivas plutónicas, consideradas como basamento, y con mucha frecuencia se observa que tanto en la superficie como en el subsuelo, estas rocas reposan indistintamente sobre formaciones del Jurásico Medio, Jurásico Inferior, Triásico o Paleozóico, por lo tanto es importante analizar la evolución tectónica de cada región y ver que es lo que ocurre de acuerdo con el área problema.

De esta manera, si durante el Paleozoico Superior la revolución orogénica Mazitzi dió origen a grandes intrusiones ígneas, principalmente granitos, queda la duda de que los granitos encontrados en la plataforma de Tuxpan-Tecolutla de edad permoTriásica, pudieran constituir apófisis los cuales al continuar perforando podrían atravesarse encontrando nuevamente sedimentos del Paleozoico Superior, posiblemente en condiciones favorables para la acumulación de hidrocarburos.

Durante el Liásico y al finalizar la orogenia Huayacocotla, los esfuerzos compresionales también dieron origen a cámaras magmáticas de rocas plutónicas, que ahora se pueden observar en la superficie; las cuales al ser alcanzadas en el subsuelo se han supuesto como de posible basamento. No obstante, las últimas perforaciones han revelado que estos cuerpos intrusivos pueden atravesarse, (Relicario No. 1, Coronado No. 1, Entabladero No. 1, etc.), encontrándose abajo de ellos, rocas Liásicas que por ahora no han mostrado indicaciones de hidrocarburos; lo cual no es factor determinante para no suponer que en algunos lugares puedan constituir verdaderos receptáculos.

Ante estas evidencias, es necesario insistir nuevamente en la interpretación de la tectónica del área y elanálsis geocronométrico de las rocas intrusivas.

\section{Fallas:}

Este aspecto estructural también es importante analizarlo, muchos autores colocan y trazan indistinta- mente una falla sin determinar su edad, y su consecuencia se muestra de repente, al encontrar una falla que afecta indistintamente a rocas paleozoicas y rocas terciarias, por lo tanto, es conveniente analizar también la edad de estas fallas y su evolución, de tal manera que en un momento dado puedan distinguirse las fallas "fosiles" o fallas que han estado actuando permanentemente, de aquellas fallas que son exclusivas de determinada epoca, porque evidentemente esto tiene mucha relación coll la acumulación de hidrocarburos.

\section{CONCLUSIONES}

Por ahora, a la roca se le ha estudiado únicamente en su aspecto estratigráfico y condiciones de depósito, sin analizar los procesos que ha sufrido durante y después de su depósito, tanto en su estructura interna así como en su conjunto como formación. Entonces se cree necesario y recomendable analizar estos procesos a través de los diferentes eventos geológicos principalmente a los tectónicos ya que de ellos depende la correcta interpretación en la búsqueda de los hidrocarburos.

Por lo tanto es necesario hacer un análisis de los siguientes aspectos:

1.-Determinar la edad de las rocas ígneas para relacionarlas con la época en que se originaron y a que formaciones afectaron.

2.-Analizar el aspecto estructural como efecto de las diferentes orogenias, principalmente las fallas. 3.-De acuerdo con los diferentes ciclos tectónicos analizar la migración de los hidrocarburos.

4.-Considerar al metamorfismo como una consecuencia de la Tectónica y no como un fenómeno aislado de donde dependen otros factores.

\section{BIBLIOGRAFIA}

\section{ALVAREZ Jr., MANUEL}

1961 Apuntes de la Clase de Geología, Paleogeografía y Téctónica de México del 50. Año U.N.A.M. Inédito,

BELOUSSOV. V. V.

1971 Problemas Básicos de Geotectónica Edit. Omega

DE CSERNA, ZOLTAN

1971 Desarrollo y Estructura de la Sierra Madre Oriental de México G.S.A. Vol. 3 No. 6.

DE SITTER, L. W.

1962 Geología Estructural Trad. Español Ediciones Omega.

KAY, MARSHALL.

1951 Mexican Geosyncline Pub. in North American Geosynclines G.S.A. Memoir

LOPEZ RAMOS, E.

1972 Estudio Geológico del Basamento Igneo y Metamórfico de las Zonas Norte y Poza Rica (entre Nautla, Ver. y Jiménez, Tamps.) Boletín de A.M.G.P. Nos. 7-9,

METZ, KARL. Manual de Geología Tectónica Edit, Omega 1963. 